\title{
THE COUMARIN COMPOSITION OF THE ROOTS
}

OF Hippomarathrum caspicum

$$
\text { A. Z. Abyshev }
$$

UDC $577.15 / 17: 582.89$

We give the results of a study of the coumarin compounds from the roots of Hippomarathrum caspicum (DC) Grossh., collected in July, 1971 in the Shemakha region (in the mountains of N. Khil'milli) Azerbaidzhan SSR.

To isolate the group of substances for invest gation, the comminuted roots $(500 \mathrm{~g})$ were extracted with chloroform. The chloroform was distilled off under vacuum, and the residue obtained $(40 \mathrm{~g})$ was chromatographed on a column of alumina $(300 \mathrm{~g}$, activity grade III), using as eluents petroleum ether, petroleum ether- chloroform $(1: 4,1: 2$, and $1: 1)$, chloroform, and methanol. This gave nine individual substances: (I) with $\mathrm{mp} 82-83.5^{\circ} \mathrm{C}$; (II) $107-109^{\circ} \mathrm{C}$; (III) $141.5^{\circ} \mathrm{C}$; (IV) $135-136^{\circ} \mathrm{C}$; (V) $229-231^{\circ} \mathrm{C}$; (VI) $105-107.5^{\circ} \mathrm{C},[\alpha]^{20}$ $-23.5^{\circ}$ (in $\mathrm{CHCl}_{3}$ ); (VII) with mp $125.5-128.5^{\circ} \mathrm{C},\left[\mathrm{c}_{\mathrm{D}}^{20}+12.25^{\circ}\right.$ (in $\mathrm{CHCl}_{3}$ ); (VIII) with mp $120-122^{\circ} \mathrm{C}$; (IX) $124-$ $126^{\circ} \mathrm{C}$, possessing properties characteristic for coumarin derivatives.

On the basis of a comparison of physicochemical properties IR spectra, $R_{f}$ values and melting points of mixtures of the compounds isolated with authentic samples, (I)-(V) were identified, respectively, as osthole, isoimperatorin, oxypeucedanin, oxypeucedanin hydrate, and umbelliferone, found previously [1] in the roots of the plant considered collected in the shore dunes close to Sumgait and Bil'gya, AzerbSSR.

On the basis of their NMR spectra and constants, coumarins (VI) and (VIII) were identified as (-)heraclenin and pangelin [4]. To determine the nature of the other substances (VI-IX) we used the results of chemical transformations and also NMR and mass spectroscopy. Thus, the NMR spectrum of (VI) had the following signals: methyl groups with $\delta 1.23$ and $1.34 \mathrm{ppm}$ (two singlets, $3 \mathrm{H}$ each); a methine proton at $\delta 3.34 \mathrm{ppm}$ (triplet, $1 \mathrm{H}$ ); a methylene proton at $\delta 4.62 \mathrm{ppm}$ (doublet, $2 \mathrm{H} ; \mathrm{J}=6 \mathrm{~Hz}$ ). In the region of aromatic protons there were four doublets with chemical shifts of $\delta, p p m, 6.44,7.92(\mathrm{~J}=10 \mathrm{~Hz}), 6.92,7.83(\mathrm{~J}=2 \mathrm{~Hz})$, due to the 3,4-protons of a coumarin nucleus and the 4',5'-protons of a furan ring, respectively. A singlet at $\delta 7.41 \mathrm{ppm}$ was due to a proton in position 5. These results agree completely with the structure proposed previously [2] for (-)-heraclenin, and this was confirmed by the preparation of isoheraclenin $(\mathrm{X})$ with $\mathrm{mp}$ $134.5^{\circ} \mathrm{C}[3]$.

The IR spectra were recorded on a UR-20 spectrometer (mull in paraffin oil) the NMR spectra on Jeol C-60 HL and Varian HA-100 spectrometers (deuterochloroform with HMDS as internal standard), and the mass spectra on an LKB-9000 instrument. The melting points were determined on a Kofler block.

\section{LIT ERATURE CITED}

1. S. Sh. Kerimov and Yu. A. Dranitsyna, Zh. Prikl. Khim., 5, 356 (1965).

2. P. W. Chow, A. M. Duffield, and P. R. Jefferies, Austr. J. Chem., 19, 483 (1966).

3. Y. N. Sharma, A. Zaman, and A. R. Kidwai, Tetrahedron, 20, 87 (1964).

4. J. Ognyanov and D. Botcheva, Dokl. Bolg. Akad. Nauk, 24 315 (1971).

Leningrad Sanitary-Hygienic Medical Institute. Translated from Khimiya Prirodnykh Soedineni, No. 4, p. 550, July-August, 1973. Original article submitted January 10, 1973.

() 1975 Plenum Publishing Corporation, 227 West 17th Street, New York, N.Y. 10011. No part of this publication may be reproduced, stored in a retrieval system, or transmitted, in any form or by any means, electronic, mechanical, photocopying, microfilming, recording or otherwise, without written permission of the publisher. A copy of this article is available from the publisher for $\$ 15.00$. 